\title{
In-situ hydrothermal synthesis of zinc oxide nanostructures using microheaters
}

\author{
Wei-Chih Lin, Yu-Ching Lin, Masayoshi Esashi, and Ashwin A. Seshia
}

\begin{abstract}
A technique for in-situ hydrothermal synthesis of transversely suspended zinc oxide nanowires ( $\mathrm{ZnO} \mathrm{NWs}$ ) using microfabricated heaters is presented. A number of issues relating to seed layer preparation, directed alignment, local heating control and the concentration of the synthesis solution are investigated for this method. It is shown that $\mathrm{ZnO}$ NWs can be synthesized and aligned from the $\mathrm{ZnO}$ seed surface to bridge two adjacent microheater elements. Moreover, hybrid $\mathrm{ZnO}$ nanotubes and nanorods are also synthesized by controlling the concentration of the synthesis solution employed. The crystalline structure of synthesized $\mathrm{ZnO}$ nanostructures are characterized by the transmission electron microscope (TEM) and selective area electron diffraction (SAED). Finally, ZnO NW devices based on proposed microheater synthesis approach are characterised for UV photoresponsivity demonstrating the potential of this approach to address practical device applications.
\end{abstract}

Index Terms - Zinc oxide nanostructures, microheaters, local nanostructure synthesis, hydrothermal synthesis and UV photodetector.

\section{INTRODUCTION}

A variety of research has reported the performance of one-dimensional (1D) $\mathrm{ZnO} \mathrm{NW}$ devices based on exceptional device properties[1]. The piezoelectric, optical and semiconducting properties of $\mathrm{ZnO}$ nanowires have been utilised to create electrically actuated high frequency nanowire resonators[2], transistors, chemical sensors and energy harvesting devices. The most commonly adopted approach for fabricating $\mathrm{ZnO}$ nanowires is the Remove-Disperse-Align technique[3]. In this method, $\mathrm{ZnO} \mathrm{NWs}$ are first separately synthesized on a growth substrate and then trans-located onto a device substrate. In most instances, this process requires precision pick-and-place alignment or other directed assembly techniques to integrate the nanowires onto specific locations for device applications[4]. Previous work has demonstrated the possibility of synthesizing transversely grown $\mathrm{ZnO}$ NWs directly on SOI substrates[5]. In this approach the nanowires

Manuscript received February 19, 2015; revised May 20, 2015; accepted July 24, 2015. Date of publication August 12, 2015; date of current version August 12, 2015. Funding support by the WPI-AIMR, Tohoku University and by the Royal Society is gratefully acknowledged.

W-C. Lin is with the Department of Mechanical and Electromechanical Engineering, National Sun Yat-sen University, Kaoshiung, 80424, Taiwan; E-mail: wc.lin@mail.nsysu.edu.tw, Tel: +886-07-5252-0000 ext. 4226

Y-C. Lin and M. Esashi are with the WPI-Advanced Institute for Materials Research, Tohoku University, Sendai, Japan.

A. A. S. is with the Nanoscience Centre, Engineering Department, University of Cambridge, CB3 OFF, UK.

Colour versions of one or more of the figures in this paper are available online at http://ieeexplore.ieee.org.

Digital Object Identifier 10.1109/TNANO.2015. were grown in a furnace at $800-915^{\circ} \mathrm{C}$ using the vapor-solid approach using an ALD deposited thin-film $\mathrm{ZnO}$ seed layer. However, in applications requiring co-integration of nanowires together with $\mathrm{CMOS}$, the high temperatures required for synthesis may not be compatible with the material stack on the device substrate.

A number of methods to integrate top-down[6] and bottom-up[7] nanofabrication approaches[4] have been proposed to address these technical limitations. Among the approaches proposed, the integration of local synthesis or directed alignment has been previously realized by using microfabricated devices. Microheater units [8] can be utilised in the MOCVD synthesis process for synthesizing $\mathrm{ZnO}$ nanostructures [9] - however, this still exposes the chip to high temperatures during the synthesis process. To avoid high temperature synthesis, CVD combined with a laser ablation approach has been studied for the fabrication of $\mathrm{ZnO}$ nanostructures at low temperature and low pressure [10]. $\mathrm{ZnO}$ nanostructures grown by using wet chemical synthesis processes have also been previously employed and previous work includes a room ambient sonochemical process to synthesize $\mathrm{ZnO}$ nanowires for fabricating UV photodetectors and gas sensors on amorphous substrates [11]. Similarly, other research reported directional control by using dielectrophoresis-driven assembly to position nanoparticles for $\mathrm{ZnO}$ NWs growth by low temperature hydrothermal synthesis [12]. Both presented methods show that the in-situ technique based on microfabricated reactor elements has potential to precisely control and synthesize nanomaterials for fabricating nanowire devices.

In this paper, we report a simple and repeatable $\mathrm{ZnO}$ NWs synthesis and alignment approach in aqueous solution using platinum ( $\mathrm{Pt}$ ) planar microheaters [13]. Fig. 1 (a) provides a schematic illustration of the $\mathrm{ZnO}$ NWs synthesis device. As shown in Fig. 1 (b), each device on this platform consists of a pair of microheaters, composed of an electroresistive Pt layer, connected with two separate conductive gold $(\mathrm{Au})$ wires. The input power can be applied via the Au conductive wire to the Pt electroresistive microheater to generate local heating for forming an oxidised $\mathrm{ZnO}$ seed layer and synthesising $\mathrm{ZnO}$ NWs as illustrated in Fig. 1 (c) and (d). Fig. 1 (c) presents the first step and the $\mathrm{Zn}$ layer is oxidized using microheaters located directly below the layer in the ambient environment. Then, horizontally grown $\mathrm{ZnO}$ NWs emerge from the sidewall of the oxidised $\mathrm{ZnO}$ seed surface based on the same local heating under a hydrothermal synthesis approach, as illustrated in Fig. 1 (d). During the synthesis process, a combination of electric field and $\mathrm{SiO}_{2}$ constraining layer directed alignment is utilised to control the direction of 
nanowire growth. We propose that this method has the potential to rapidly and locally synthesize nanostructures in-situ on silicon substrates without the need for assembly processes.
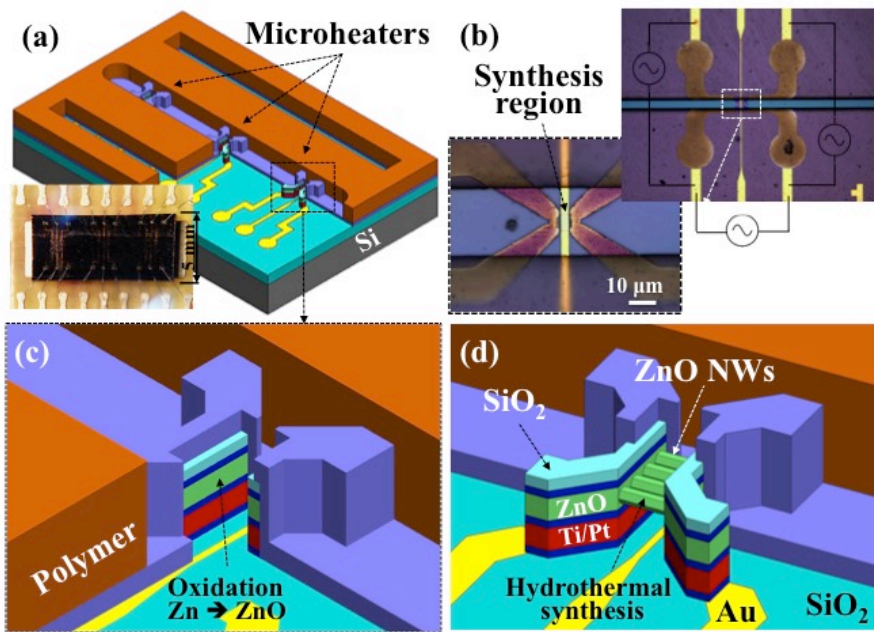

Fig. 1 (a) Illustration of the $\mathrm{ZnO} \mathrm{NW}$ synthesis device; (b) Optical pictures of the fabricated microheater device; (c) Illustration of the oxidation process for forming $\mathrm{ZnO}$ seed layer and (d) Illustration of $\mathrm{ZnO} \mathrm{NWs}$ synthesis by using hydrothermal synthesis.

\section{EXPERIMENTAL DETAILS}

Nanowire synthesis is governed by factors that include the energy input required for synthesis, precursor materials for growth, and defining the growth texture of the substrate. To obtain a desired nanofabricated device with defined geometry, morphology and material properties, these parameters have to be controlled precisely during the synthesis process. For example, in hydrothermal synthesis, the morphology, length and diameter of synthesized $\mathrm{ZnO}$ NWs are mainly influenced by the reactant concentration (precursor), heating temperature (synthesis energy) and surface conduction of seed layer (growth texture). In this research, the growth of $\mathrm{ZnO} \mathrm{NWs}$ is based on the hydrothermal synthesis method. For synthesising well-controlled geometries of $\mathrm{ZnO}$ nanostructures, optimisation of the growth parameters for hydrothermal synthesis is necessary [14]. Therefore, several issues, including the condition of the seed layer and local heating, are studied to discover optimized synthesis parameters as described below.

\section{A. Fabrication and characterisation of microheaters}

Microheater Fabrication. Several microfabrication processes were utilized to construct the microheater devices and the fabrication process is illustrated sequentially in Fig. 2 (a) to (h). As described previously [15], the process commences with fabricating the $\mathrm{Cr} / \mathrm{Au}$ conductive wires as shown in Fig. 3 (a). The thickness of $\mathrm{Cr}$ and $\mathrm{Au}$ layer are around 20 and $200 \mathrm{~nm}$, respectively. The conductive Au wire is embedded within the $\mathrm{SiO}_{2}$ layer to eliminate the step coverage effect. Then, photolithography and dry processes are utilized to pattern the multilayer, including Ti, Pt, Cr, $\mathrm{Zn}$ and $\mathrm{SiO}_{2}$, for microheater fabrication, as illustrated in Fig. 2 (b) and (c). Similar processes were repeated to produce the cover layer for isolating the synthesis solution from contact with microheaters.
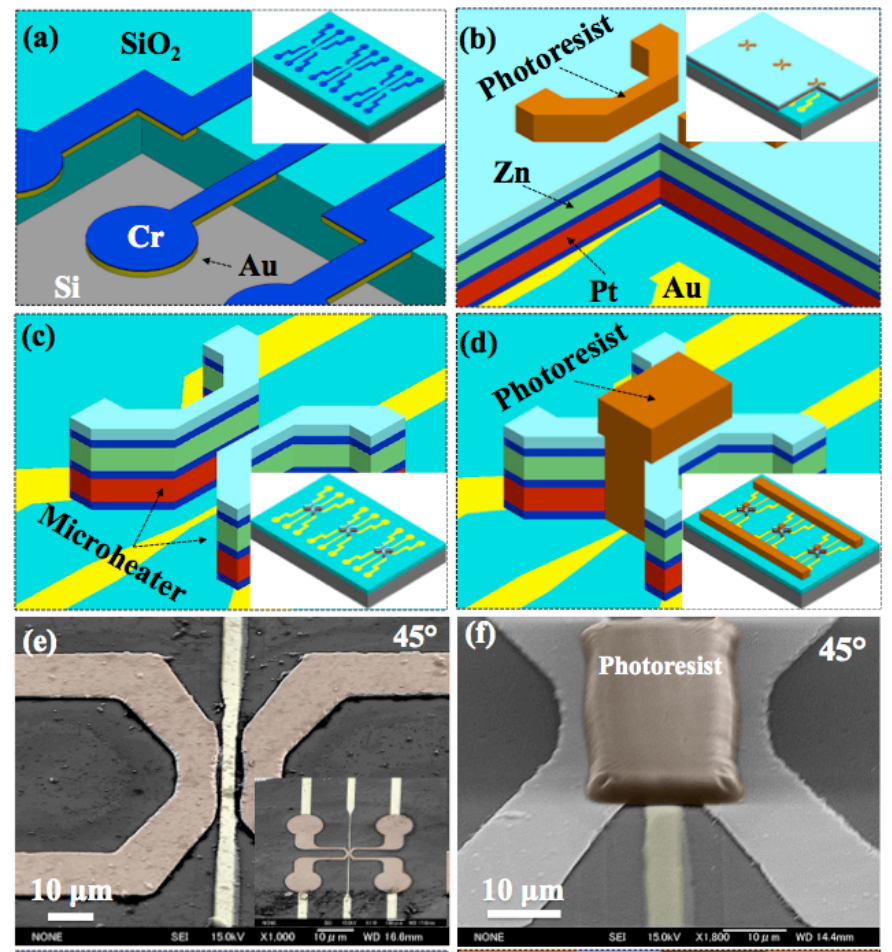

(g)

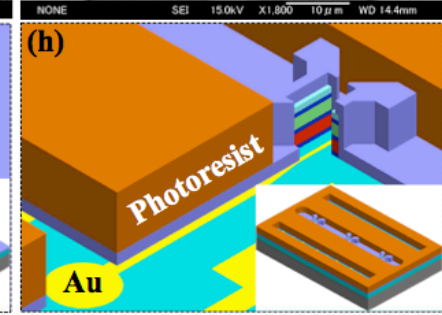

Fig. 2 (a)-(h): Schematic description and SEM images of the fabrication sequence for the microheater array.

Characterization of Microheaters. In conventional hydrothermal synthesis, a synthesis temperature of $90{ }^{\circ} \mathrm{C}$ is frequently used for $\mathrm{ZnO} \mathrm{NWs}$. In this work, the microheater devices are first characterized to establish a temperature-power database to meet this requirement. The microheater devices are operated by applying voltages from 0 $\mathrm{V}$ peak-to-peak $\left(\mathrm{V}_{\mathrm{pp}}\right), 10 \mathrm{kHz}$ to $10 \mathrm{~V}_{\mathrm{pp}}$ at a voltage ramp rate of $0.1 \mathrm{~V} / \mathrm{sec}$ under ambient conditions. An infrared camera (TVS-500EX, NEC) with $18.5 \mu \mathrm{m}$ mapping resolution and microlens is used to measure the generated temperature profile. The chip was placed on a commercial XYZ stage under ambient environment and measurements were conducted inside a light-insulated enclosure. Fig. 3 (b-d) shows measured temperature distribution images by applying 4, 6 and $10 \mathrm{~V}_{\mathrm{pp}}$ and the results for temperature distribution in the microheater zone are then tabulated. As can be seen from the measured temperature distribution, due to a high thermal conductivity of $\mathrm{Pt}$ and $\mathrm{Au}$ materials, the generated heat is rapidly conducted to the entire microheater surface and to the $\mathrm{Au}$ conductive wires. However, this issue can be partly mitigated by adopting low thermal conductivity constraining layers such as $\mathrm{SiO}_{2}$ or $\mathrm{Si}_{3} \mathrm{~N}_{4}$. Therefore, $\mathrm{ZnO} \mathrm{NWs}$ are only synthesized at the edge of the microheaters as a result. 
(a)
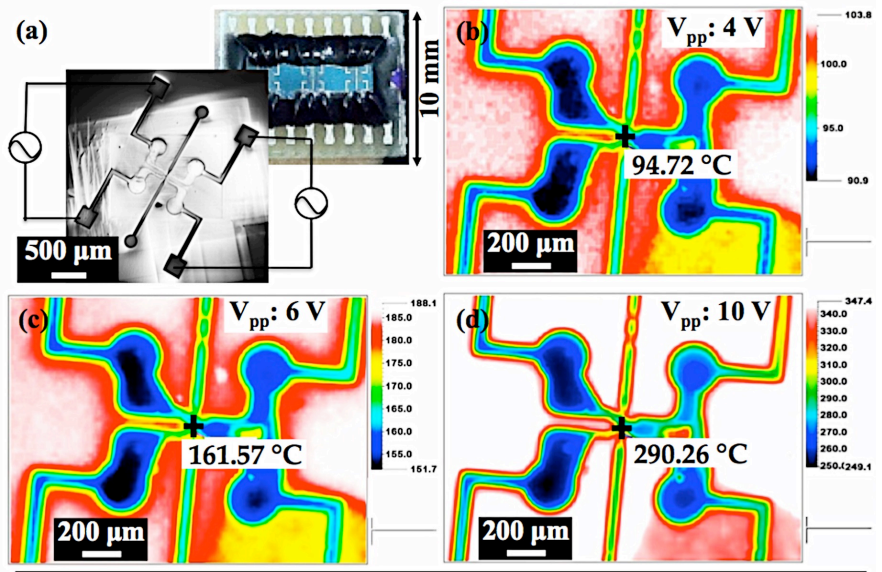

(e) $2\left(\mathrm{~V}_{\mathrm{pp}}\right)$

$54.86^{\circ} \mathrm{C}$

\begin{abstract}
$4\left(\mathrm{~V}_{\mathrm{pp}}\right)$
\end{abstract}
$94.72{ }^{\circ} \mathrm{C}$
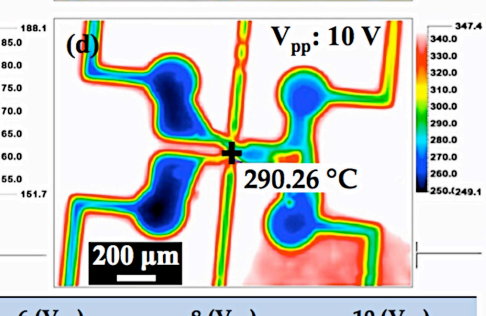

$6\left(\mathrm{~V}_{\mathrm{pp}}\right)$

\begin{abstract}
$8\left(\mathrm{~V}_{\mathrm{pp}}\right)$
\end{abstract}
$10\left(\mathrm{~V}_{\mathrm{pP}}\right)$

$229.26^{\circ} \mathrm{C} \quad 290.26^{\circ} \mathrm{C}$

Increasing ratio: $0.1(\mathrm{~V} / \mathrm{Sec})$

Fig. 3 (a) The packaged chip and device unit; (b-d) Temperature distribution images measured for various applied voltages and (e) table showing the temperature.

\section{B. Growth-texture seed layer}

Numerous seed layer materials have been previously utilised to provide the necessary conditions for nanostructure synthesis. The roles of the seed layer material are to provide the starting textured substrate as a grain-growth template for nanostructure synthesis. Normally, the geometries of the synthesized 1D nanostructures are based on the growth surface condition of the seed layer, such as the grain size, grain distribution, grain boundary and deposited surface roughness and uniformity. Nanostructures are basically grown from the grains of the seed layer so that the diameters of nanostructures are determined by the surface conditions of deposited seed layers. Our previous experiments show that the smaller the size of the nucleated $\mathrm{ZnO}$ seeds, the thinner the diameter of the synthesized $\mathrm{ZnO}$ NWs [16]. On the other hand, the desired crystallographic orientation can be determined by the seed layer and this crystallographic orientation can provide an epitaxial growth surface condition during nanostructure synthesis. Then, the nanostructures are synthesized along with this determined growth orientation.

Deposition of the $\mathrm{Zn}$ layer. In the hydrothermal synthesis approach, $\mathrm{ZnO}$ (in nanoparticle and thin film formats), are commonly utilised as seed layers for $\mathrm{ZnO}$ NWs synthesis. In this paper, we proposed an oxidation method using microheaters to form a suitable epitaxial growth surface and create fine grains of nucleated $\mathrm{ZnO}$ seeds for $\mathrm{ZnO} \mathrm{NW}$ synthesis [16]. The first step is to deposit a $\mathrm{Zn}$ layer on the Pt microheater layer. By considering two mentioned requirements, a fine grained and desired crystallographic orientation on a smooth seed layer surface is necessary. Several deposition conditions are studied for a good quality $\mathrm{Zn}$ layer. The employed RF sputtering powers commenced from $45 \mathrm{~W}$ up to $300 \mathrm{~W}$ under $0.5 \mathrm{~Pa}$ chamber pressure and $8 \mathrm{sccm}$ of Ar gas. The deposition rate and surface roughness relative to the sputtering power are shown in Table 1 . The average thickness of the deposited $\mathrm{Zn}$ layer was measured from three selected positions on five different samples and the total deposition time was 3 minutes. The surface roughness of the deposited Zn layer was measured using the AFM that showed a decrease in surface roughness with decreasing sputtering power. The average roughness ( $\mathrm{Ra}$ ) of the $\mathrm{Zn}$ layer is 91 (300 W), $45.3(200 \mathrm{~W}), 30.2(100 \mathrm{~W}), 22.6(70 \mathrm{~W}), 16.0(60 \mathrm{~W})$ and $15.6 \mathrm{~nm}(45 \mathrm{~W})$ following measurements using an AFM.

Table. 1 The deposition ratio and surface roughness of $\mathrm{Zn}$ layer as functions of different sputtering powers.

\begin{tabular}{|c|c|c|c|}
\hline Power (W) & $\begin{array}{c}\text { Deposition rate } \\
(\mathrm{nm} / \mathrm{min})\end{array}$ & \multicolumn{2}{|c|}{ Surface roughness (nm) } \\
\hline 300 & 448 & Ra: 91.0 & Rq: 119 \\
\hline 200 & 211 & Ra: 45.3 & Rq: 52.2 \\
\hline 100 & 91 & Ra: 30.2 & Rq: 30.6 \\
\hline 70 & 69 & Ra: 22.6 & Rq: 27.1 \\
\hline 60 & 51 & Ra: 16.0 & Rq: 22.9 \\
\hline 45 & 47 & Ra: 15.6 & Rq: 24.2 \\
\hline
\end{tabular}

Figure 4 (a-d) shows the surface morphology of each deposited Zn layer using $300 \mathrm{~W}, 100 \mathrm{~W}, 70 \mathrm{~W}$ and $45 \mathrm{~W}$ sputtering powers, respectively. As can be seen from Fig. 4 (a) and (b), the SEM pictures clearly show that the shape of the grain size is hexagonal which means the $\mathrm{Zn}$ layer is oxidised during the deposition. There is no hexagonal $\mathrm{ZnO}$ structure synthesised by using the $70 \mathrm{~W}$ and $45 \mathrm{~W}$ deposition power as shown in Fig. 4 (c) and (d).

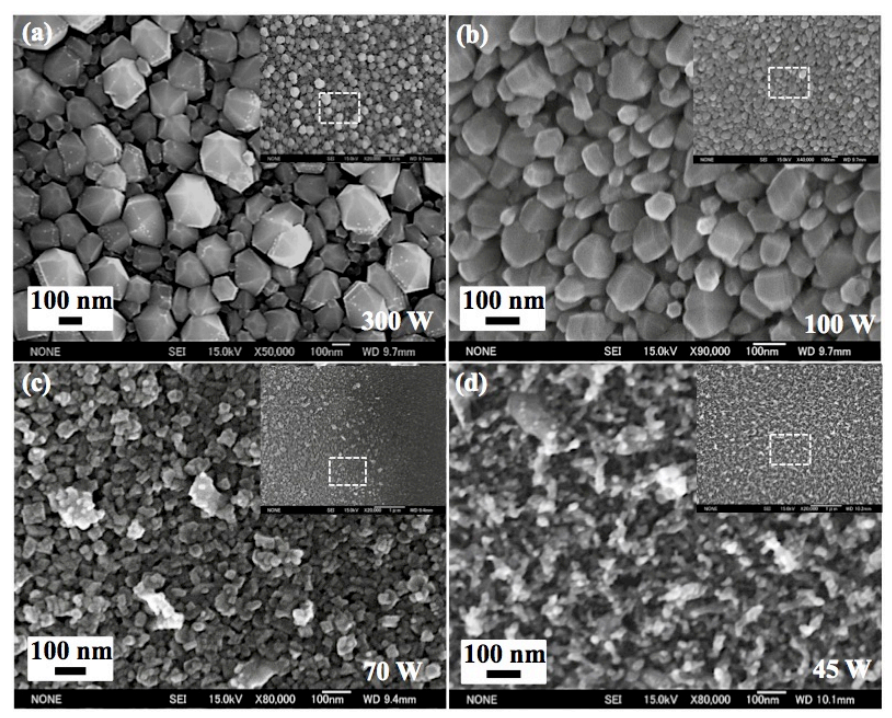

Fig. 4 The surface morphology of the deposited Zn layer for (a) $300 \mathrm{~W}$, (b) $100 \mathrm{~W}$, (c) $70 \mathrm{~W}$, and (d) $45 \mathrm{~W}$ of sputtering power.

To investigate the hexagonal structure, we utilised the Raman Spectrum to identify the layers, which are deposited by using $300 \mathrm{~W}$ and $200 \mathrm{~W}$ powers, where there are two broad peaks presented in the range of $300-450$ and $550-600 \mathrm{~cm}^{-1}$, as presented in the corresponding measurement shown in Fig. 5. These regions attribute to $\mathrm{ZnO}$ peaks [17] which are $\mathrm{E}_{2}$ (high) $438 \mathrm{~cm}^{-1}, A_{1}$ (high) $381 \mathrm{~cm}^{-1}, \mathrm{~A}_{1}$ (TO) $378 \mathrm{~cm}^{-1}, \mathrm{E}_{1}$ (TO) 409 $\mathrm{cm}^{-1}, \mathrm{~A}_{1}(\mathrm{LO}) 571 \mathrm{~cm}^{-1}, \mathrm{~A}_{1}(2 \mathrm{LA}) 483 \mathrm{~cm}^{-1}, \mathrm{E}_{1}(\mathrm{LO}) 583 \mathrm{~cm}^{-1}$ and $\mathrm{E}_{2}$ (TO) $335 \mathrm{~cm}^{-1}$. The Raman peaks at $483 \mathrm{~cm}^{-1}$ is associated with the $\mathrm{A}_{1}$ (2LA) mode of $\mathrm{ZnO}$ signal and is prominently seen in the green $(300 \mathrm{~W})$ and yellow line $(200$ $\mathrm{W})$ respectively. This clearly corresponds to the $\mathrm{ZnO}$ nanorods and oxidation might be occurred during the deposition process. Similarly, the $\mathrm{Zn}$ layer deposited at $100 \mathrm{~W}$ power still 
shows evidence of oxidised $\mathrm{ZnO}$ nanostructures and also some low signal peaks (blue line) revealed in these two regions. Therefore, the applied sputtering power to deposit the $\mathrm{Zn}$ layer should be less than $100 \mathrm{~W}$. This also can be supported by the measured Raman spectrums and the sputtering power of 70 (red line) and $45 \mathrm{~W}$ (black line) have a smooth and obvious $\mathrm{Zn}$ peak at $566 \mathrm{~cm}^{-1}$ and there is no obvious $\mathrm{ZnO}$ peaks revealed for these cases.

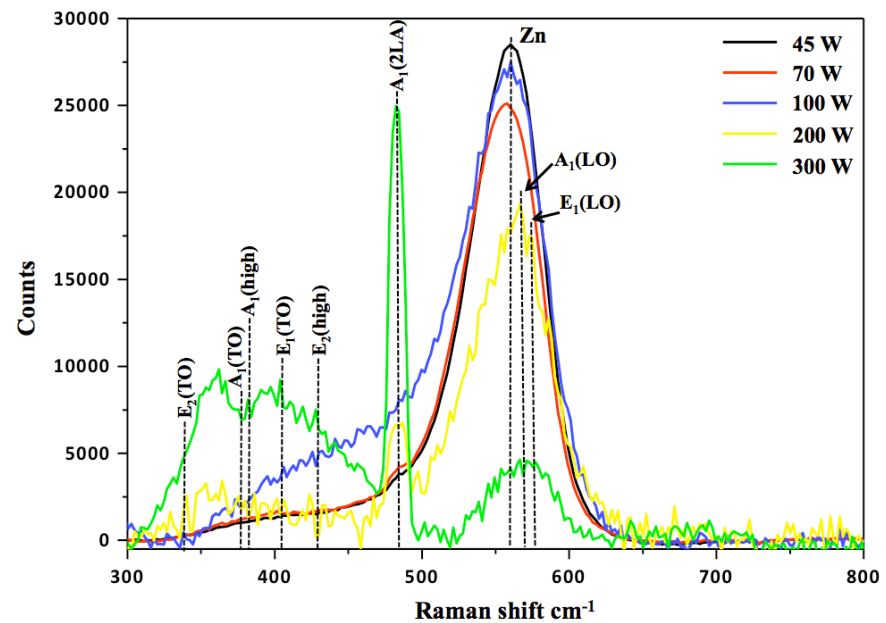

Fig. 5 Raman spectrum for the $\mathrm{Zn}$ layers deposited by different sputtering powers corresponding to the cases shown in Table 1. and Fig. 4.

Although decreasing the sputtering power can reduce the growth of oxidized $\mathrm{ZnO}$ NWs during the deposition process, low deposition power does not enable sufficient adhesion for the deposited $\mathrm{Zn}$ layer. As revealed in Fig. 6 (a, c and d), the initial $\mathrm{Zn}$ layer deposited by using $40 \mathrm{~W}$ sputtering power was oxidized by applying an $8 \mathrm{~V}(0.8 \mathrm{~W})$ heating voltage and $30 \mathrm{~V}$ bias voltage between two microheaters to form the $\mathrm{ZnO}$ seed layer. However some catenarian $\mathrm{Zn}$ nanostructures, confirmed through SEM and EDS, as seen from the images in Fig $5(a-b)$, form between two microheaters after the oxidation process. $\mathrm{Zn}$ nanoparticles might move from the deposited $\mathrm{Zn}$ layer and locate in the ground substrate driven by the electric field. To consider the trade-off between the issues of oxidation and adhesion, a sputtering power of $70 \mathrm{~W}$ was utilised for the $\mathrm{Zn}$ layer deposition in this research.
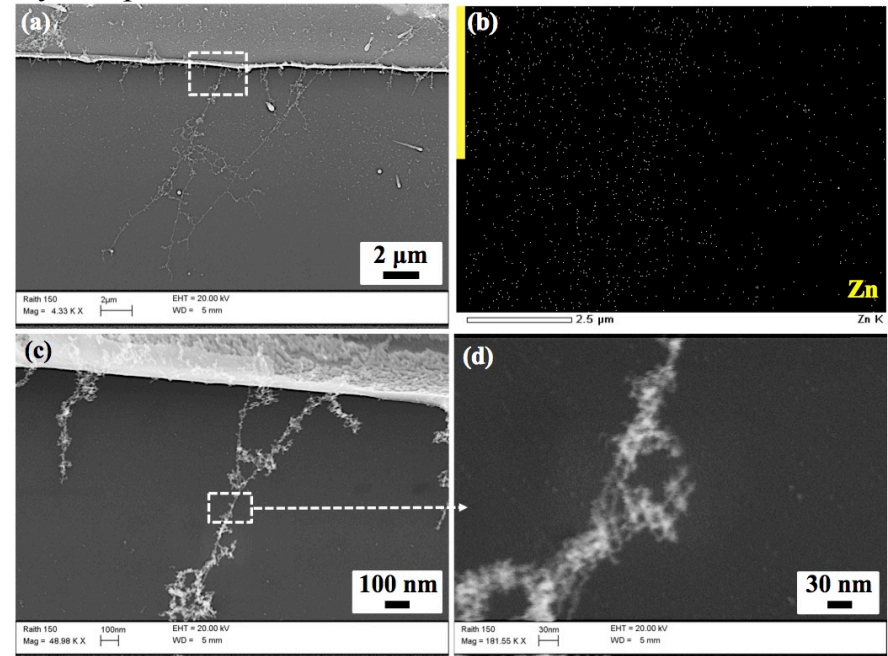

Fig. 6 (a-d) SEM and EDS pictures of synthesized catenarian $\mathrm{ZnO} \mathrm{NWs}$ following an oxidation and alignment process.
Preparation of oxidised $\mathrm{ZnO}$ seed layer. Fig. 7 (a) presents the formation of oxidized $\mathrm{ZnO}$ seed layer by operating the microheaters under ambient conditions. The reaction of zinc ions and oxygen starts from the $\mathrm{Zn}$ top surface progressing to the bottom of the layer. By using this method, the fine grain size and $\mathrm{ZnO}$ nuclei can be grown on the surface of the oxidised $\mathrm{ZnO}$ layer. This research investigated oxidation of a variety of $\mathrm{Zn}$ layer thicknesses, ranging from $50 \mathrm{~nm}$ to 500 $\mathrm{nm}$. Then, we tested the oxidized $\mathrm{ZnO}$ seed layer under hydrothermal synthesis methods for locally growth $\mathrm{ZnO} N W s$. Fig. 7 (b-c) demonstrates two different thicknesses of $\mathrm{ZnO}$ seed layers that are oxidised by applying $10 \mathrm{~V}_{\mathrm{pp}}, 10 \mathrm{kHz}$ under ambient conditions for 10 minutes. Next, the whole device is immersed into $20 \mathrm{mM}$ of zinc nitrate and HMTA solution and $4 \mathrm{~V}_{\mathrm{pp}}, 100 \mathrm{kHz}$ heating voltages are applied to the microheaters for 90 minutes to synthesize the ZnO NWs. As can be clearly seen from the SEM pictures in Fig. 7 (b-c), ZnO NWs are fully grown and uniformly synthesized onto the entire oxidised $\mathrm{ZnO}$ seed surface. Therefore, this experimental result proves that oxidation by using a microheater-based approach is feasible. An oxidised $\mathrm{ZnO}$ seed layer with nanoscale features can be also achieved by this proposed microheater-heating method.

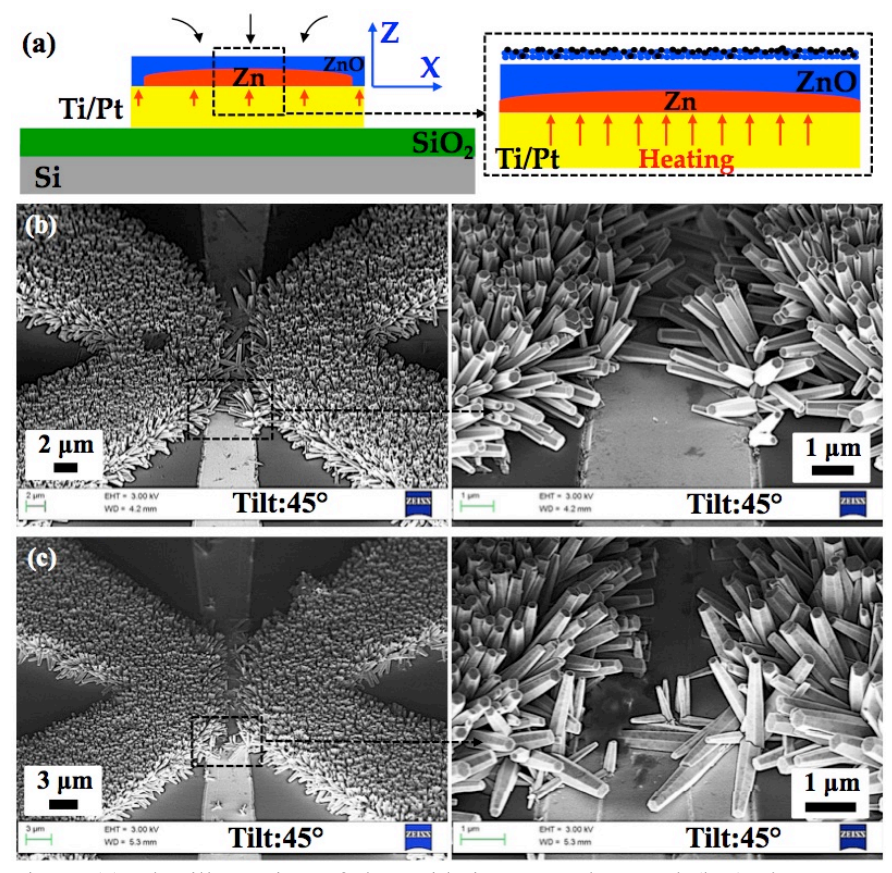

Fig. 7 (a) The illustration of the oxidation procedure and (b-c) show SEM images of synthesized $\mathrm{ZnO}$ NWs by a local aqueous heating method after $\mathrm{Zn}$ oxidation.

\section{Synthesis of transversely suspended $\mathrm{ZnONWs}$}

Constraining layer. In this work, various thicknesses of $\mathrm{SiO}_{2}$, ranging from $25 \mathrm{~nm}$ to $500 \mathrm{~nm}$, are deposited onto the oxidised $\mathrm{Zn}$ layer as a constraining layer for controlling the growth direction. The $\mathrm{SiO}_{2}$ constraining layer is utilized to prevent the growth of $\mathrm{ZnO} N W s$ in the vertical direction. The topside of the $\mathrm{Zn}$ surface is isolated from the synthesis solution so that $\mathrm{ZnO}$ nanostructures are only synthesized on the exposed sidewall area. Fig. 8 from (a) to (d) show SEM images of the oxidised $\mathrm{ZnO}$ seed layer covered by a $25 \mathrm{~nm}, 50$ $\mathrm{nm}$ and $100 \mathrm{~nm}$ thick $\mathrm{SiO}_{2}$ layer and the oxidation follows the 
same process as presented in Fig. 7 (b-c). Then, these devices are dipped into the synthesis solution for 2 hours for synthesis by the conventional hydrothermal method. As can be seen from Fig. 8 (b-c), $25 \mathrm{~nm}$ and $50 \mathrm{~nm}$ thick $\mathrm{SiO}_{2}$ does not provide sufficient isolation to prevent $\mathrm{ZnO} \mathrm{NWs}$ synthesis. The $\mathrm{SiO}_{2}$ layer is peeled off by synthesized $\mathrm{ZnO} \mathrm{NWs}$ that may result due to a non-conformal $\mathrm{SiO}_{2}$ layer deposition and pinholes present in the constraining layer. The synthesis solution can react with $\mathrm{ZnO}$ seed layer via these pinholes to grow $\mathrm{ZnO} \mathrm{NWs}$ ultimately resulting in peeling off the entire $\mathrm{SiO}_{2}$ layer. A $100 \mathrm{~nm}$ thick $\mathrm{SiO}_{2}$ layer is sufficiently constraining and is found to prevent $\mathrm{ZnO}$ NWs synthesis in the vertical direction as shown in Fig. 8 (d). The $\mathrm{ZnO}$ NWs grow on the sidewall region of the oxidised $\mathrm{ZnO}$ seed surface in this case.
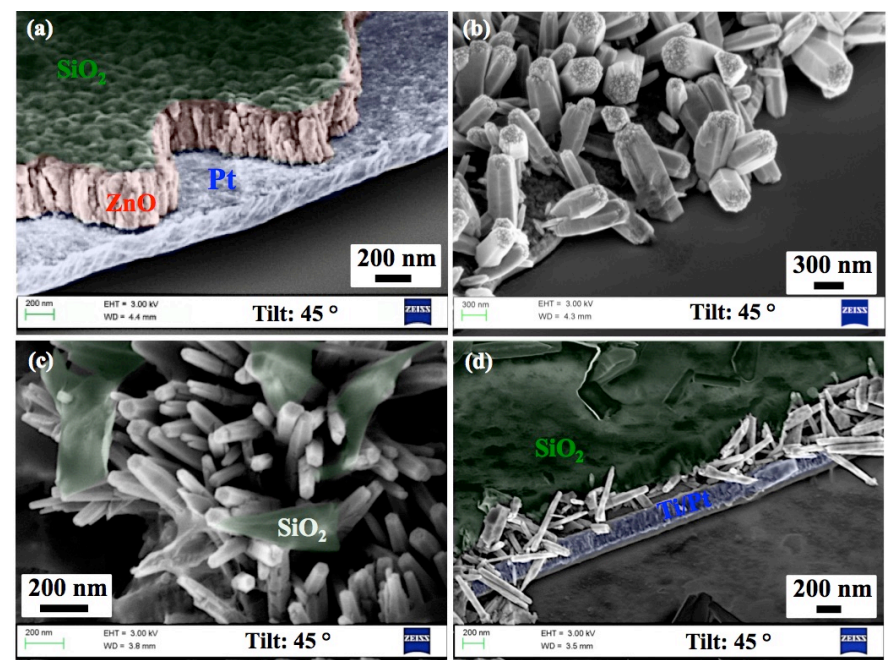

Fig. 8 (a) The initial $\mathrm{Zn}$ layer covered by a constraining $\mathrm{SiO}_{2}$ layer; (b) and (c) The identification of the thickness of constraining $\mathrm{SiO}_{2}$ layer for preventing ZnO NWs synthesis.

Electric field assistance. A further alignment approach is to set up an electric field to control the direction of nanowire growth between the two microheaters during the synthesis process. By using the parameters discussed above, the device covered by a $100 \mathrm{~nm}$ constraining $\mathrm{SiO}_{2}$ layer is first oxidised to form a $\mathrm{ZnO}$ layer and dipped into the synthesis solution. Next, the heating voltage is set to $6 \mathrm{~V}_{\mathrm{pp}}$ applied between the two microheaters and the frequency is varied $10 \mathrm{kHz}$, as shown in Fig. 2, to the left microheater. The $6 \mathrm{~V}_{\mathrm{pp}}$ bias voltages with a set of frequency, including $10 \mathrm{kHz}, 100 \mathrm{kHz}, 1$ $\mathrm{MHz}$ and $10 \mathrm{MHz}$, are applied between two microheaters. Fig. 9 (a) and (b) show the synthesized $\mathrm{ZnO}$ NWs by applied $6 \mathrm{~V}_{\mathrm{pp}}$, $10 \mathrm{kHz}$ and $6 \mathrm{~V}_{\mathrm{pp}}, 1 \mathrm{MHz}$ bias voltages, respectively. As can be seen from the SEM pictures, the $\mathrm{ZnO}$ NWs growth starts from the left side to bridge the gap between two microheaters after 50 minutes. The higher the frequency of the applied bias voltage the smaller diameter of the resulting nanowires.

Although the above experiment shows that the $100 \mathrm{~nm}$ $\mathrm{SiO}_{2}$ constraining layer can prevent vertical $\mathrm{ZnO}$ NWs synthesis, there is still some peeling of the constraining layer that is observed. Therefore, the heating voltage is decreased to $4 \mathrm{~V}_{\mathrm{pp}} 10 \mathrm{kHz}$ and the bias voltage is increased to $10 \mathrm{~V}_{\mathrm{pp}}, 10$ $\mathrm{MHz}$. However, $\mathrm{ZnO}$ nanostructures are still gradually grown on the top surface of microheaters during an hour synthesis, as shown in Fig. 7 (c). Then the synthesized $\mathrm{ZnO}$ nanostructure aggregates to a $\mathrm{ZnO}$ ball with an emerged single $\mathrm{ZnO} \mathrm{NW}$.
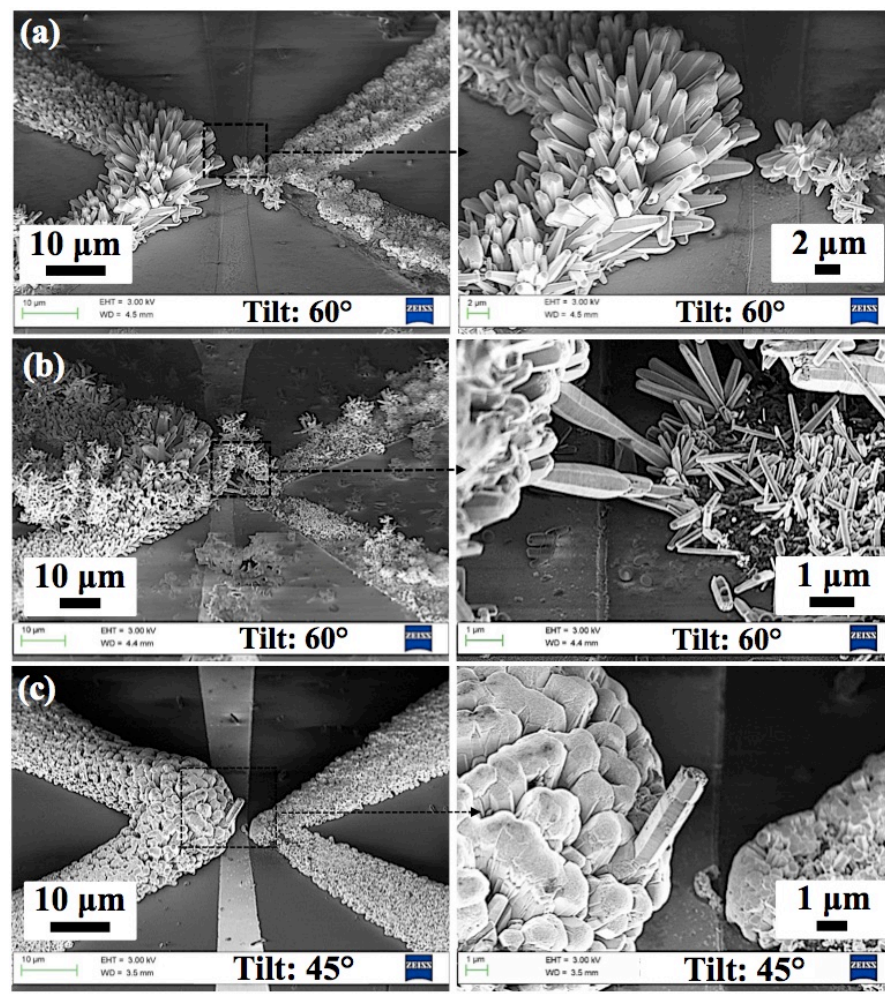

Fig.9 (a-c) Synthesized ZnO NWs by applying fixed 6 Vpp bias voltages at various frequencies including $10 \mathrm{kHz}, 1 \mathrm{MHz}$ and $10 \mathrm{MHz}$.

\section{RESULTS AND DISCUSSION}

Testing of oxidized seed layer in the sidewall region. The thickness of the constraining $\mathrm{SiO}_{2}$ layer is increased to $500 \mathrm{~nm}$ for a further series of experiments. The $\mathrm{Zn}$ layer is oxidised to create the $\mathrm{ZnO}$ seed layer in a manner identical to the earlier protocol. The diffusion of oxygen and zinc ions starts from the uncovered sidewall of the $\mathrm{Zn}$ surface and then the oxidised $\mathrm{ZnO}$ seed layer is created, as illustrated in Fig. 10 (a). After a 10 minute oxidation process, few regions of constraining $\mathrm{SiO}_{2}$ are randomly removed by physical etching. Next, the whole device is dipped into the synthesis solvent and the $4 \mathrm{~V}_{\mathrm{pp}} 10 \mathrm{kHz}$ heating voltage is applied to the both microheaters for 15 minutes synthesis. As can be seen in Figs. 10 (b) - (e), ZnO NWs grow only on the sidewalls and oxidised $\mathrm{ZnO}$ areas where the constraining $\mathrm{SiO}_{2}$ has been removed. Furthermore, it clearly shows that the density of synthesized $\mathrm{ZnO} \mathrm{NWs}$ in the apex part of the microheater is decreased from the tip to the root regions of the electrodes. This clearly is qualitatively consistent with the fact that the density of $\mathrm{ZnO} \mathrm{NWs}$ is based on the applied heating voltages and times, as shown in Fig. 10 (d) and (e).

Experiments of ZnO NWs synthesis using microheaters. After the oxidation process, the same parameters are used and experiments are repeated. The synthesized nanowires at time intervals of 1,2 and 6.5 hours are shown in Figs. 11 (a), (b) and (c), respectively. Both microheaters are operated by applying $4 \mathrm{~V}_{\mathrm{pp}}, 10 \mathrm{kHz}$ heating 

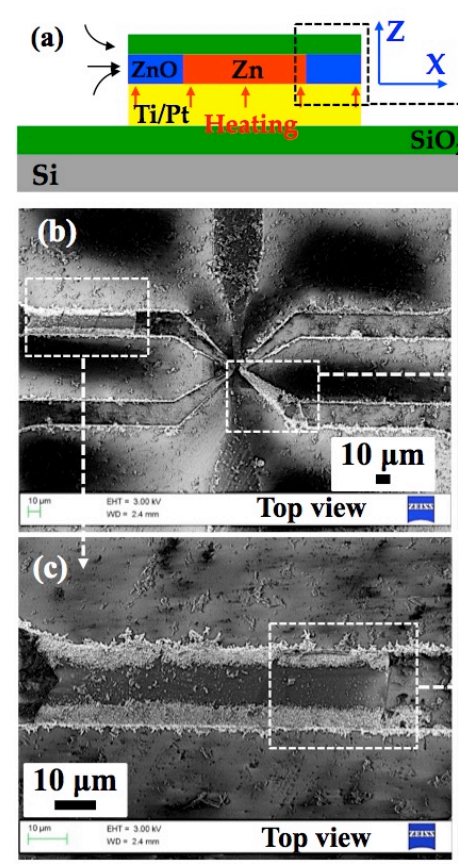

Fig.10 (a) The illustration of $\mathrm{Zn}$ layer oxida layer; and (b-e) identification of the oxidised region of the $\mathrm{ZnO}$ seed layer by synthesized $\mathrm{ZnO}$ NWs.
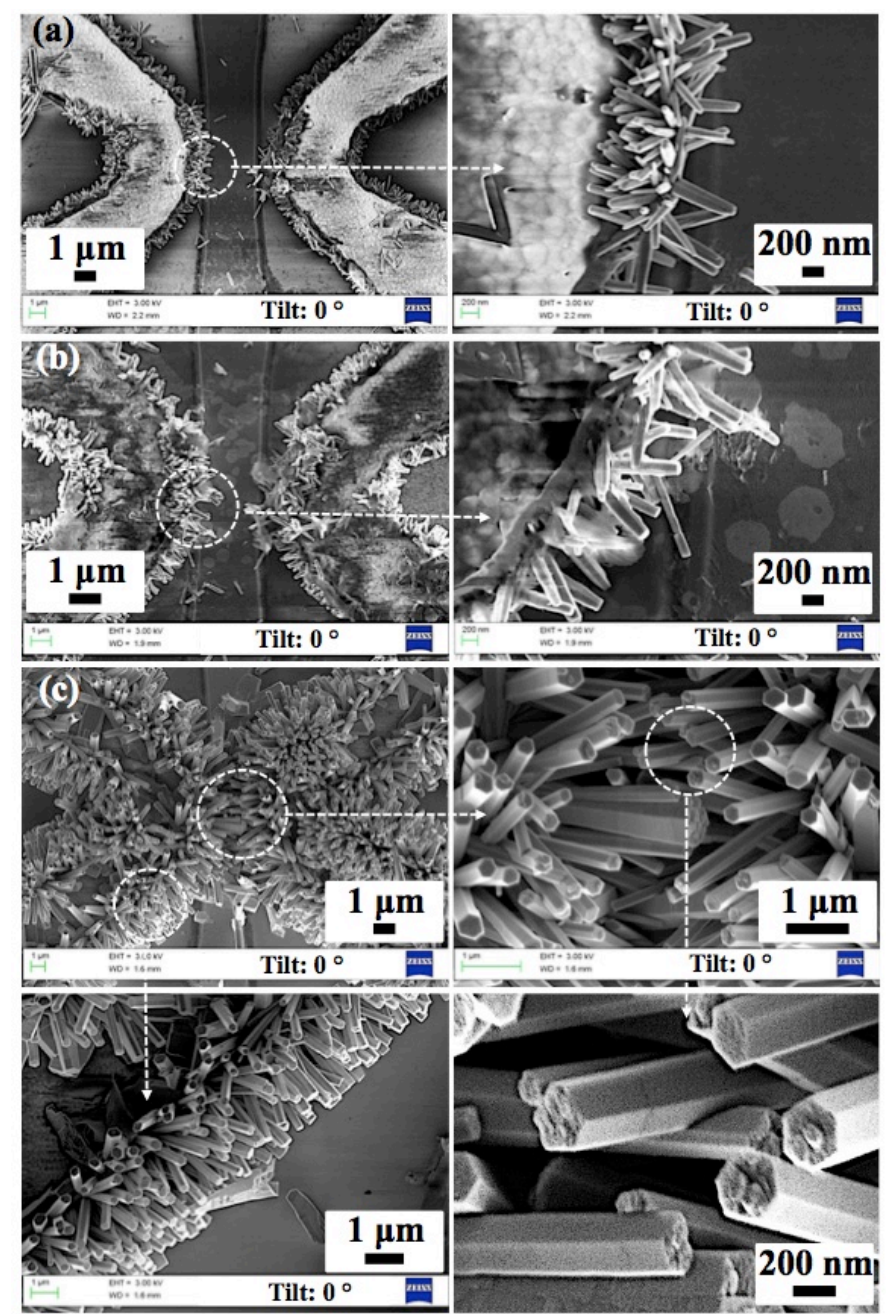

Fig.11 (a-c) Sequential SEM images of synthesized and aligned ZnO NWs taken at different time intervals. voltage and a further $10 \mathrm{~V}_{\mathrm{pp}}, 10 \mathrm{MHz}$ bias voltages is set to simultaneously align the grown $\mathrm{ZnO} \mathrm{NWs}$ between two microheaters. After 6.5 hours synthesis, the $500 \mathrm{~nm}$ thick $\mathrm{SiO}_{2}$ constraining layer can still prevent the $\mathrm{ZnO} \mathrm{NWs}$ being synthesized on the top surface of microheaters. As can be seen from Fig. 11 (c), the growth of $\mathrm{ZnO}$ NWs can be controlled well by using this hybrid approach and $\mathrm{ZnO} \mathrm{NWs}$ are synthesized from the sidewall of the oxidised $\mathrm{ZnO}$ seed layer to form transversely suspended nanowires between the two microheaters. Furthermore, the synthesized $\mathrm{ZnO}$ NWs are physically in contact as seen in the intermediate section SEM detail in Fig. 11 (c). However, there is still some peeling at the edge of constraining layer, as shown in Fig. 11 (c). This might be caused by the increasing diameter and fresh growth of $\mathrm{ZnO}$ NWs over time but it is possible to be eliminated by various treatments, such as reducing the thickness of the $\mathrm{ZnO}$ seed layer, adding a capping solution to restrict increase in lateral nanowire dimension and by lowering the concentration of the synthesis solution.

We also tested a single microheater for the synthesis of $\mathrm{ZnO}$ NWs without applying the electric field assistance approach. The $\mathrm{ZnO}$ NWs presented in Fig. 12 (a) are synthesized on by applying $4 \mathrm{Vpp}, 10 \mathrm{kHz}$ heating voltage under $20 \mathrm{mM}$ of zinc nitrate and HMTA solution for 8.5 hours. By comparison with Fig. 12 (b), there is no dramatic length increase after 17 hours synthesis. However, the $\mathrm{ZnO}$ NWs morphs into $\mathrm{ZnO}$ rods as the diameter progressively increases. Furthermore, several $\mathrm{ZnO}$ seed grains result on the tip of the $\mathrm{ZnO}$ rods towards the end of the process and new $\mathrm{ZnO}$ nanostructures grow from these regions, as can be seen in Fig. 12 (b). Unfortunately, it shows that thin $\mathrm{SiO}_{2}$ constraining layer could not sufficiently prevent vertical growth of $\mathrm{ZnO}$


Fig.12 (a) and (b) SEM pictures of the $\mathrm{ZnO}$ NWs and hybrid nanorods synthesized after 8.5 hours and 17 hours, respectively. 
NWs and peeling occurred from the edge after a long synthesis time. Then, $\mathrm{ZnO}$ NWs were synthesised almost on the whole surface of the oxidized $\mathrm{ZnO}$ seed layer. Moreover, rough nanocrystalline $\mathrm{ZnO}$ seeds anchored on the $\mathrm{SiO}_{2}$ substrate near the microheater patterns during hydrothermal synthesis.

To investigate the phenomenon of hybrid nanorod synthesis, different concentration-dependent synthesis experiments were conducted. Fig. 13 (a) and (b) provide TEM images of synthesized $\mathrm{ZnO}$ nanostructures. The synthesized $\mathrm{ZnO}$ nanostructures in Fig. 13 (a) and (b) are synthesized under the $20 \mathrm{mM}$ and $5 \mathrm{mM}$ of the zinc nitrate and HMTA solution for 3 hours, respectively. The low concentration solution is used to simulate the synthesis reaction in the last few hours, as for the experiment presented in Fig. 12 (b). Similarly, several new $\mathrm{ZnO}$ seed grains and nanotubes are synthesized on the tip surface of nanorods, as can be seen from Fig. 13 (b). These hybrid $\mathrm{ZnO}$ nanotubes and rods are synthesized corresponding following $\mathrm{Zn}$ concentration decrease in the synthesis solution. Furthermore, it also clearly shows that the aspect ratio of the synthesized $\mathrm{ZnO}$ NWs is affected by the concentration. From the TEM and selected area electron diffraction (SAED) measurements, the crystalline structure of the synthesized $\mathrm{ZnO} \mathrm{NWs}$ and hybrid $\mathrm{ZnO}$ rods with nanotubes can be categorized as hexagonal Wurtzite structure and space group- 186 .
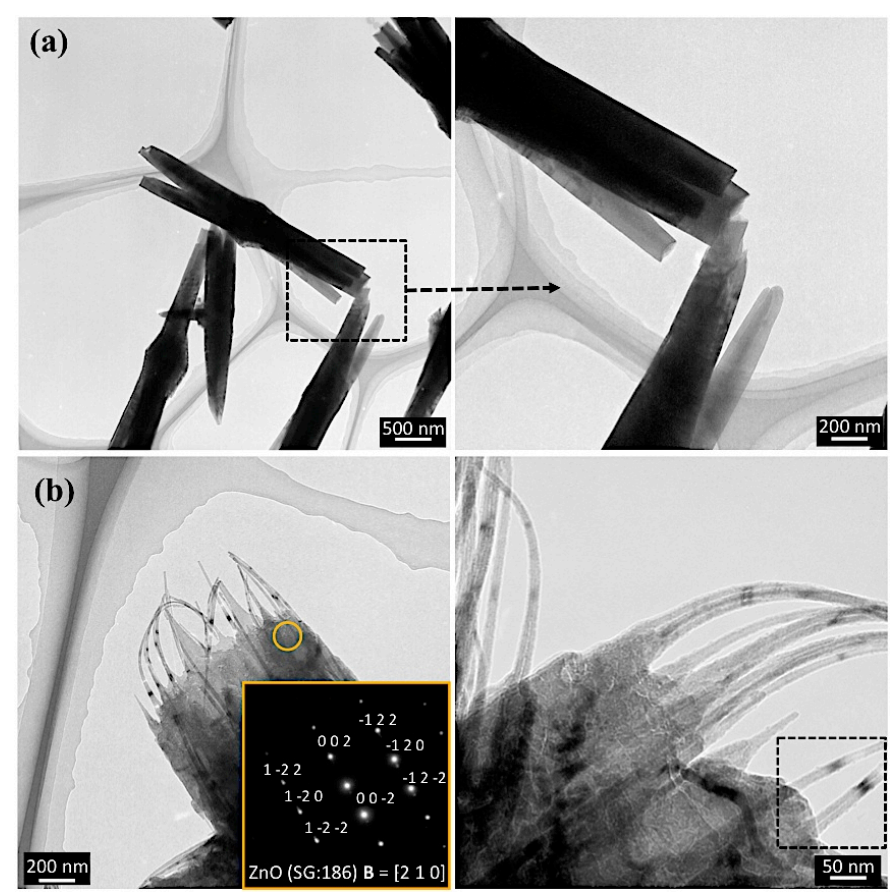

Fig.13 (a) TEM images of ZnO NWs synthesized using $20 \mathrm{mM}$ of zinc nitrate and HMTA synthesis solution; (b) Synthesized hybrid $\mathrm{ZnO}$ nanostructures using $5 \mathrm{mM}$ synthesis solution.

Device Case Study. ZnO NWs are sensitive to UV light and this property can be exploited for several applications, such as in photodetectors and chemical sensors. Figure 14 (a) and (b) demonstrate results obtained from I-V characterisation and UV photoresponsivity of the $\mathrm{ZnO} \mathrm{NWs}$ fabricated using the approach outlined in this work. The I-V property of the device was characterized for bias voltages ranging from $-1 \mathrm{~V}$ to $1 \mathrm{~V}$ under ambient conditions. In the dark condition, the I-V curve was slightly asymmetric and nonlinear, originating from the existence of barriers between the Ti/Pt electrodes and the $\mathrm{ZnO}$ NWs [18]. The I-V response showed a current increase from $0.5 \mathrm{~mA}$ to $0.8 \mathrm{~mA}$, and then to $1.5 \mathrm{~mA}$ at $1 \mathrm{~V}$ bias voltage, as the device was subjected to UV radiation of wavelength equal to $254 \mathrm{~nm}$ and $365 \mathrm{~nm}$.
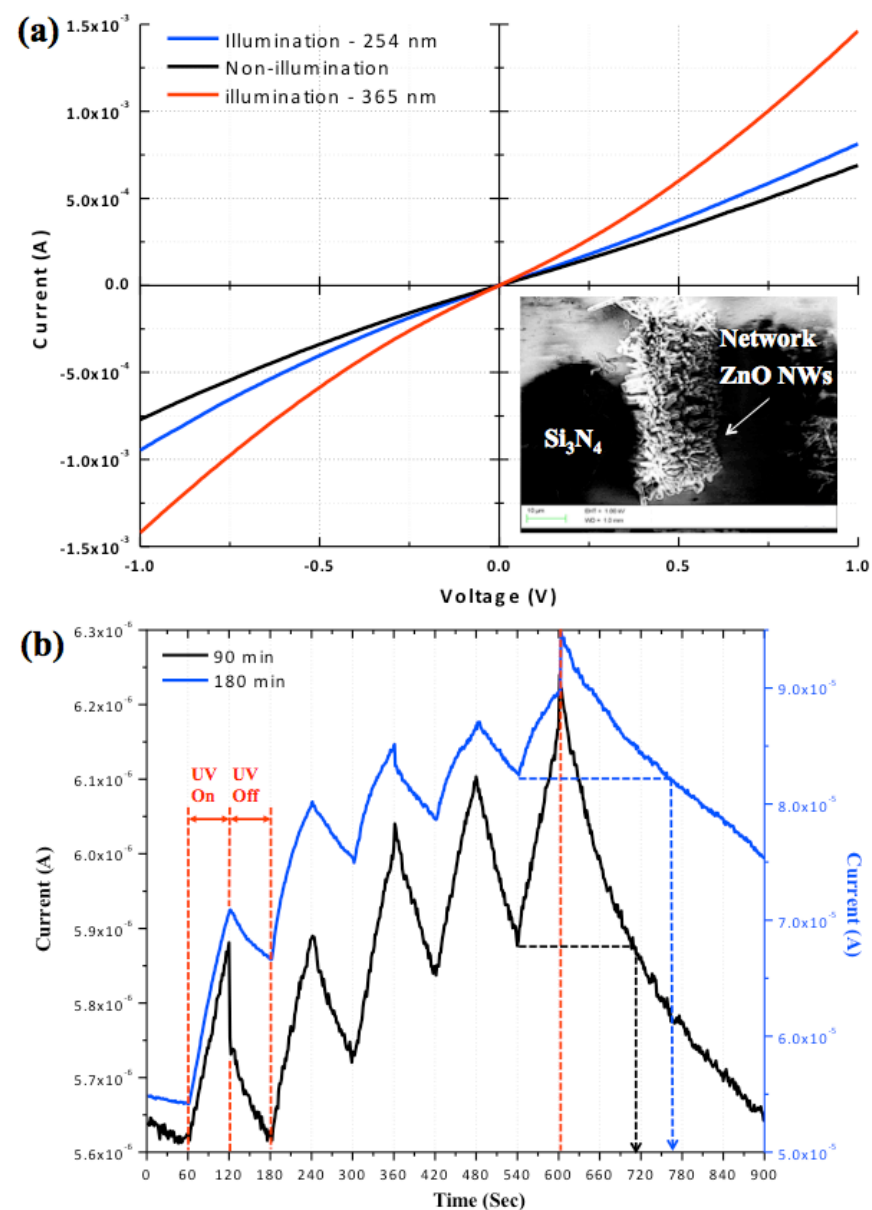

Fig.14 (a) I-V characteristics of the network $\mathrm{ZnO}$ NWs device in dark (black line), $254 \mathrm{~nm}$ (blue line) and $365 \mathrm{~nm}$ (red line) UV illumination; (b) Photo-response characteristics for two different devices by repeatedly switching the UV radiation $(365 \mathrm{~nm})$ on and off.

Two more devices (with differing synthesis times of 90 and 180 minutes respectively) were separately tested under the same UV $(\lambda=365 \mathrm{~nm})$ illumination system to characterize photoresponse times, repeatability and response stability over time. Figure 14 (b) presents the response of the two devices where device current is measured as a function of time, when the $365 \mathrm{~nm}$ UV light is periodically switched on and off.

\section{CONCLUSION}

This paper presents an approach towards the in-situ synthesis of $\mathrm{ZnO}$ nanostructures based on microheaters. Several issues, including seed layer preparation, local heating synthesis, constraining-layer and electric field directed alignment, and the concentration of synthesis solution, are 
investigated to optimize the synthesis procedure. As demonstrated in Fig. 11 (c), transversely suspended ZnO NWs are synthesized and aligned by using this combinative approach between two microheater elements in aqueous solution. Optimal heating and alignment voltages are found (4 $\mathrm{V}_{\mathrm{pp}}, 10 \mathrm{KHz}$ and $10 \mathrm{~V}_{\mathrm{pp}}, 10 \mathrm{MHz}$ respectively) for synthesizing the bridged $\mathrm{ZnO} \mathrm{NWs}$ and the synthesis is operated under $20 \mathrm{mM}$ of zinc nitrate and HMTA solution for 6.5 hours.

With regard to $\mathrm{ZnO}$ seed layer preparation, the appropriate parameters to deposit the initial $\mathrm{Zn}$ layer for oxidation to create a $\mathrm{ZnO}$ seed layer is $70 \mathrm{~W}$ for sputtering resulting in a fine roughness of $\mathrm{Zn}$ surface without compound $\mathrm{ZnO}$ nanostructures. Then, the $\mathrm{Zn}$ layer is fully oxidised by the 10 $\mathrm{V}_{\mathrm{pp}}, 10 \mathrm{KHz}$ applied heating voltage for 10 minutes in the ambient. ZnO NWs are directly synthesized on the oxidised $\mathrm{ZnO}$ seed surface by applying $4 \mathrm{~V}_{\mathrm{pp}}, 100 \mathrm{KHz}$ heating voltage under $20 \mathrm{mM}$ of zinc nitrate and HMTA solution for 90 minutes.

Additionally, various thicknesses of $\mathrm{SiO}_{2}$ constraining layer are studied to constrain $\mathrm{ZnO}$ nanowire synthesis to the horizontal direction. To ensure appropriate physical isolation during the synthesis process, the thickness of constraining layer needs to be increased up to $500 \mathrm{~nm}$ to operate under the required temperatures. Moreover, an electric field alignment approach is utilised to simultaneously assist ZnO NWs synthesis along with the horizontal direction.

Synthesis is carried out under $5 \mathrm{mM}$ and $20 \mathrm{mM}$ of zinc nitrate and HMTA solution respectively to correlate synthesis conditions to the geometry of the synthesized $\mathrm{ZnO}$ nanostructure. During the 17 hour synthesis, several nanotubes and tiny $\mathrm{ZnO}$ grains are found to grow on the tip surface of nanorods. TEM and SAED analysis reveal the crystalline structure of the synthesized nanorods and hybrid nanostructures as hexagonal Wurtzite structure and spacing group -186 .

Finally, $\mathrm{ZnO} \mathrm{NW}$ devices fabricated using this approach were characterized as UV photodetector elements. Preliminary experiments were conducted to characterizeI-V response and UV photoresponse under ambient conditions demonstrating the feasibility of the fabrication approach to address practical device applications.

\section{ACKNOWLEDGEMENTS AND NOTES}

Funding support by the WPI-AIMR, Tohoku University and by the Royal Society is gratefully acknowledged.

This paper is based on concepts originally presented at the $25^{\text {th }}$ IEEE MEMS conference, held in Paris, France, 29 January - 2 February 2012, and is an expansion of the abstract as printed in the Technical Digest of this meeting.

\section{REFERENCES}

[1] Z. L. Wang, "Zinc oxide nanostructures: growth, properties and applications," Journal of Physics-Condensed Matter, vol. 16, no. 25, pp. R829-R858, Jun, 2004.
[2] M. A. Khaderbad, Y. Choi, P. Hiralal et al., "Electrical actuation and readout in a nanoelectromechanical resonator based on a laterally suspended zinc oxide nanowire," Nanotechnology, vol. 23, no. 2, pp. 025501-1-025501-7, Jan, 2012.

[3] B. E. Alaca, "Integration of one-dimensional nanostructures with microsystems: an overview," International Materials Reviews, vol. 54, no. 5, pp. 245-282, Sep, 2009.

[4] M. C. P. Wang, and B. D. Gates, "Directed assembly of nanowires," Materials Today, vol. 12, no. 5, pp. 34-43, May, 2009.

[5] J. F. Conley, L. Stecker, and Y. Ono, "Directed integration of $\mathrm{ZnO}$ nanobridge devices on a Si substrate," Applied Physics Letters, vol. 87, no. 22, pp. 223114-1-223114-3, Nov, 2005.

[6] J. K. Hwang, S. Cho, E. K. Seo et al., "Large-Area Fabrication of Patterned ZnO-Nanowire Arrays Using Light Stamping Lithography," Acs Applied Materials \& Interfaces, vol. 1, no. 12, pp. 2843-2847, Dec, 2009.

[7] M. W. Li, R. B. Bhiladvala, T. J. Morrow et al., "Bottom-up assembly of large-area nanowire resonator arrays," Nature Nanotechnology, vol. 3, no. 2, pp. 88-92, Feb, 2008.

[8] B. D. Sosnowchik, L. Lin, and O. Englander, "Localized heating induced chemical vapor deposition for one-dimensional nanostructure synthesis," Journal of Applied Physics, vol. 107, no. 5, pp. 051101-1-051101-14, Mar 1, 2010.

[9] Y. J. Kim, J. M. Jeon, J. H. Choi et al., "ZnO nanostructures with controlled morphologies on a glass substrate," Nanotechnology, vol. 21, no. 26, pp. 265603-1-265603-6, Jul, 2010.

[10] T. Hirate, S. Sasaki, W. C. Li et al., "Effects of laser-ablated impurity on aligned $\mathrm{ZnO}$ nanorods grown by chemical vapor deposition," Thin Solid Films, vol. 487, no. 1-2, pp. 35-39, Sep, 2005.

[11] A. P. Nayak, T. C. Lin, D. Lam et al., "UV and Oxygen Sensing Properties and Space Charge Limited Transport of Sonochemically Grown ZnO Nanowires," Nanoscience and Nanotechnology Letters, vol. 4, no. 10, pp. 977-982, Oct, 2012.

[12] V. Pachauri, A. Vlandas, K. Kern et al., "Site-Specific Self-Assembled Liquid-Gated ZnO Nanowire Transistors for Sensing Applications," Small, vol. 6, no. 4, pp. 589-594, Feb, 2010.

[13] L. Wei-Chih, Y. Yao-Joe, H. Gen-Wen et al., "Selective local synthesis of nanowires on a microreactor chip," Sensors and Actuators A (Physical), vol. 130-131, pp. 625-632632, 14, 2006.

[14] S. Baruah, and J. Dutta, "Hydrothermal growth of $\mathrm{ZnO}$ nanostructures," Science and Technology of Advanced Materials, vol. 10, no. 1, pp. 013001-1-013001-18, Mar, 2009.

[15] W. C. Lin, Y. C. Lin, C. J. Shih et al., "Local synthesis and alignment of zinc oxide nanowires in aqueous solution using microheaters," 2012 IEEE 25th International Conference on Micro Electro Mechanical Systems (MEMS), pp. 452-455455, 2012, 2012.

[16] L. Weichih, A. A. Seshia, W. Ching-Chen et al., "Catalyst-free synthesis of zinc oxide nanostructures by microheaters in the ambient environment," Proceedings of the 2011 6th IEEE International Conference on Nano/Micro Engineered and Molecular Systems (NEMS 2011), pp. 897-900900, 2011, 2011.

[17] K. A. Alim, V. A. Fonoberov, M. Shamsa et al., "Micro-Raman investigation of optical phonons in $\mathrm{ZnO}$ nanocrystals," Journal of Applied Physics, vol. 97, no. 12, pp. 223114-1-223114-3, Jun 15, 2005.

[18] Z. M. Liao, J. Xu, J. M. Zhang et al., "Photovoltaic effect and charge storage in single $\mathrm{ZnO}$ nanowires," Applied Physics Letters, vol. 93, no. 2, pp. 1-3, Jul, 2008. 